\title{
Transformation and Planning of Production Space in Beishan Village, Zhuhai
}

\author{
Hui $\mathrm{Li}$ \\ Department of Tourism Management \\ Zhuhai College of Jinlin University \\ Zhuhai, China
}

\author{
Shuai Yang \\ Department of Tourism Management \\ Zhuhai College of Jinlin University \\ Zhuhai, China
}

\begin{abstract}
Based on the theory of space production, this paper analyzes the dominant factors of space production history of Beishan village and uses the spatial criticism theory to examine and analyze the current situation. In view of the crisis of Beishan village's spatial transition, this paper tries to make planning and design on the scale of "people-oriented" and "fairness of space", and hopes to explore the related issues of Beishan village and bring enlightenment to the transformation and planning of Beishan village.
\end{abstract}

Keywords-space production; spatial transition; Beishan Village; planning

\section{INTRODUCTION}

Since the reform and opening up, the speeding up of urban economic development has also accelerated the transformation and update of rural space in urban areas. However, such problems as destruction of space resources, disappearance of traditional culture and deterioration of space ecology have also occurred frequently in rural transformation. The Beishan village's spatial pattern is one of urban villages surrounded by traditional villages, and the spatial transformation often faces a variety of contradictions. Henry Lefebvre's theory of space production has created a basic research perspective and theoretical basis for the research of space-related issues. The spatial production theory can be used as an effective tool to analyze the spatial reconstruction and planning of research objects, and the theoretical value can be applied to space production and transformation in rural areas. From historical patterns evolution of space production to the criticism on spatial production in Beishan village, this paper provides an overall exploration of the current situation and problems of space production in Beishan village of Zhuhai with "space production" as the research content and mode.

\section{PERIODIC SPACE PRODUCTION AND FORMATION ChANGE Process of BEISHAN VILlaGE}

Lefebvre pointed out that social space was a social product, and changes of social formation often accompanied by changes of space form. Society in each period will historically have a unique space pattern. Due to historical reasons, the administrative ownership of Beishan village has changed several times. In modern times, Zhuhai County was formally established on May 1, 1953, and Beishan village was governed by Zhuhai County. It was incorporated into
Zhongshan County in late 1958. In April 1961, Zhuhai County was resettled, and Beishan village was still under its jurisdiction. In August 1980, Zhuhai officially became one of the three major special economic zones of the day and Beishan Village became an administrative village subordinated to Nanping Town. Before reform and opening, Beishan village was still dominated by traditional agriculture with no significant improvement in social productivity or significant change in spatial form in the long run. After reform and opening, agricultural production was gradually reduced and transferred to industrial space, and the traditional spatial shape changed obviously. According to the difference of dynamic factors of space production, the village form change of Beishan village since 1970 has been divided into the following stages:

\section{A. The Spatial Production and Form in Rural Autonomous Region \\ 1) Productivity Improvement Primary Industry \\ in} Beishan Village

From the 1970 s to the 1980 s, the commodity economies entered villages in China. In 1982, Beishan also piloted the project of contract responsibility system for production in advance. By 1984, all the production teams of Beishan groups had implemented the contract responsibility system for production. Beishan at this time mainly implemented the household contract responsibility system, and people operated independently. Although the productivity at this stage was improved, it was still mainly human-induced, and the products produced were mainly agricultural and forest products with lower output value. However, from the perspective of development, the improvement of productivity in Beishan village in this period provided a good political foundation and capital accumulation for space transformation of Beishan village.

\section{2) The transfer of Industry and labor force}

With the development of rural productivity and the shift of production methods, the number of people engaged in agriculture in Beishan village has been decreasing year by year. After the founding of Zhuhai in 1980, the state encouraged the individual and private-owned economy, which developed the business in Beishan village. After economic development of many years, farming and livestock breeding enterprises in Beishan village have also gradually developed towards industrial and tertiary industries, and 
agricultural land have shifted to commercial land. At this time, some residents worked in the village or went out as migrant workers, making a lot of surplus labor turning to industries such as industry, transportation, construction, commerce and trade. The main driving force of space production of this time still came from human, but the industry was shifting to the more profitable industry and commerce.

\section{B. Market-driven Space Production and Spatial Form}

1) To attracte investment and construct commercial and industrial land

In the 1990s, economy developed rapidly, the market went to mature gradually, the driving mechanism of township enterprises changed from endogenous to foreign investment. Obviously, individual business and industry can no longer meet the needs of social production, but the development of Beishan village was badly in need of land. In 1984, with the help and guidance of the district government, Beishan village used the ready-made ancestral halls and production team sites as the workshops through cooperation, joint ventures and compensation trade, and established export-oriented enterprises such as Beishan flower factory, Daye Flower factory and Garment factory successively. From 1985 to 2001, Beishan village had built standard plants covering more than 55,000 square meters in all. By the end of 2014, there are 315 industrial parks and industrial and commercial enterprises along the street (including shops of all sizes) in addition to the two large-scale farmers' markets in the whole Beishan Community. Among them, there are 20 industrial enterprises, 157 commercial ones, and 51 catering and 87 service ones.

The production of space material offered primitive capital accumulation of collective economy in Beishan village, and agricultural production had almost been replaced by agricultural industry. This phase shows that the space production in Beishan village has quietly transformed into "the production of space itself", and dramatic increase in industrial space in industrial space has resulted in the compression of natural space. The space production in this stage is no longer a trial production of an individual or partial but an overall space for production. The increase of industrial and commercial land also causes the space operation to be capitalized, and the land resources have also become the major means of appreciation for the rural areas.

\section{2) Increasing demand for living space}

In the early 1980s, new residence of Beishan people increased gradually. Some compatriots in Beishan, who lived in Hong Kong and Macao, also made an application to the government for house sites. The township party branch and township government at that time allotted the vacancies in the village for villagers to build houses. In addition to the living demands increase of local residents, with the development of economy, most of the staff in Beishan Industrial Park and Nanping Science and Technology Industrial Park chose to live nearby. Therefore, it is also necessary to meet the demands of the immigrants' living space. During this period, most of the old houses were tore down or rebuilt as rented houses driven by the market economy. Increasing income by using space, villagers transformed the role of peasants or migrant workers into landlords. The urgent needs of living space and the mass space production have resulted in the shortage and congestion of space. In addition to being used for living, some space was used as wares for renting. The real estate industry gradually sprouted, and "the production of space itself" began to take shape driven by the capital market.

\section{3) Infrastructure development in the village}

The capital accumulation has caused a large influx of immigrant population, and the requirements of rural transformation industrial production for infrastructure level have also gradually improved. Therefore, Party branches and village committees of Beishan village financed the environmental construction in the village from 1984 to 1991 and invested more than 500,000 yuan in transformation of the roads and ditches in the village and unified putting and collection of trash. The original stone road in the village was converted into a concrete road. Drainage pipes were dredged to change the open channel to covered ones and straighten out the channels to increase water discharge. From 1984 to 2000 , the state allocated about 70,000 yuan and collectively raised a total of 520,000 yuan to purchase large-diameter pipes from Zhuxiandong and Dishuiyan to draw streams into the village, and set up water pipelines for households, which rewrote the history of the village taking water by wells. At this time, the transformation of space is in progress, for the old houses are constantly being demolished, and new roads are paved continuously.

Residents enjoying the benefits of space production also do well for adapting to the new opportunities brought by economic development better. Under the condition of market economy, the accumulation of funds in Beishan village has increased, so there are sufficient funds for space optimization and renovation.

\section{Government-led Space Production and Spatial Pattern}

\section{1) Land acquisition, changes of land ownership}

Since March 1985, Zhuhai Bureau of Land and Resources has started the unified collection of $3290 \mathrm{mu}$ of arable land collectively owned by Beishan villagers, implying that the ownership of land and the control of space production were handed over to the government. By September 1988, all the collectively-owned land in the village will be entirely collected by the municipal government except for the reserved areas for industrial production and living for peasants. After the land was expropriated, the Beishan peasants were converted to residents, and the grain was uniformly compensated by the municipality in accordance with the residents' treatment. The collective ownership of Beishan village was successively used by the municipal government for urban construction. After Beishan's collective arable land was collected, the municipal government allocated another $81 \mathrm{mu}$ of privately owned land for the Beishan farmers to serve as their future housing land. These privately-owned lands are also used for collective use and are not allocated to individuals. After Beishan village has become an urban community, the construction of any building needs to be reviewed by the 
relevant government departments. Any building that is constructed without being reported and approved will be regarded as illegal. After the government levied the land, the process of spatial transformation became orderly and space production was dominated by the government.

2) "Collective" transformed to "industrial economy" after villages changed to residential community

In September 2001, Beishan village committee was renamed Beishan neighborhood committee. The social management affairs was handed over to the community residents committee after villages changed to residential community, and the original collective economic organization of the administrative village was transformed into a collective economic organization of the community. Beishan collective economic organizations registered as "Beishan industrial co. LTD. in Xiangzhou District of Zhuhai" in Business Sector in Zhuhai on October 12, 2000, Zhuhai. After registering, Beishan Industrial Co., Ltd. has successively transformed Beishan Market and stores in industrial areas, and obtained land to build a "Beishan Square" with a building area of 4,200 square meters with the support of the municipal government. The square, stores, Beishan Commercial Street, and Beishan Market are rolled into a commercial district that integrates the purchase of daily necessities and food.

The transfer of the collective economy of Beishan village from the primary industry to the secondary and tertiary industries is a manifestation of the increase in spatial productivity. At present, the collective economy of Beishan village relies on the space dividend as its main economic source.

\section{3) Construction of rural residential community}

In 2003, the Beishan Community was brought into line with the urban construction. The Committee of Neighborhood Committee and the shareholders agreed to use the fund raised by shareholders and funded by the Beishan Industrial Co., Ltd. to build Beishan New Village named Xiu $\mathrm{Yu}$ Garden in the east of the community. Xiu Yu Garden is newly-built modern housing in the reserved land on the premise of retaining residential land in the old village. Due to the professional planning and design of the construction, the streets of the community are well-ordered, and the space between buildings is also very reasonable. After the completion of the first three phases of the Beishan village Housing Project, the stage IV is still to be arranged as another community.

The spatial form of Beishan village has changed from the original decentralized residence to the centralized residential community. Most of the villagers own a new and an old house, new home for their living, and an old for renting. Houses of the old village are currently dominated by immigrants and very saturated.

4) Government takes the lead in planning the construction of Beishan Village

In order to promote the transformation of the village in Zhuhai, Zhuhai Municipal Government established the "Civilized Community Office Group for the Transformation of Old Villages in Zhuhai" in 2000. The ancestral buildings and traditional buildings in Beishan village were wellmaintained and repaired thanks to the spontaneous funding of the Zhuhai Municipal Government and villagers in Beishan village. In 2002, the Zhuhai municipal government asked the South China University of Technology to conduct research on the historical and cultural resources of Beishan village at that time, and compiled the "Plan of Protection and Utilization of Beishan village, Nanping Town, Zhuhai City". The plan has established protection and utilization measures for Beishan village's historical and cultural resources. Due to the large number of historical buildings in Beishan village and they were scattered in the village, the overall demolition is not suitable for Beishan village, and it will destroy the original historic buildings undoubtedly. Therefore, how to rationally develop and use the traditional building on the basis of protection and maintenance is a major issue for the government.

In January 2014, Zhuhai municipal government decided to carry out urban renewal of the Beishan area and merged Beishan old village and old industrial area into the renewal area. The governments took the lead to layout and deploy Beishan village space. The project development also focuses on transformation and protection of inheritance. For the Beishan old village, protective development will be carried out. For the industrial area, demolition of old buildings and new buildings will be carried out. The construction and reconstruction will also implement the basic principles of cultural relic protection and historical and cultural heritage. According to the plan, Beishan village will introduce the planning concept of "cross-axis", adding relevant functional support, and bringing culture, entertainment, tourism, and business together. Space production will present a pattern of blocking and division of labor.

\section{CRISIS OF BeISHAN VILlage's Space Production}

After the reform and opening up, the spatial production pattern of Beishan village has undergone several transformations, and the transition period is up to a dozen years, even though they are short, there are several years. The rapid change in spatial pattern has caused many problems in the process of space transformation of Beishan village. The emphasis on the topic of space production critique not only is a reflection on space production, but a further understanding of the phenomenon of space production and an exploration of a better spatial production model as well.

\section{A. Critique of Space Production Capital of Beishan Village}

\section{1) Space serves to capital}

Looking at the relationship between space production and capital in Beishan village, we can see that, on the one hand, space production shows the purpose and trend of serving capital gain. On the other hand, the involvement of capital makes the space be standardized and scaled up like commodities. While capital brought in funds, it also intensified the exploitation of space and changed the historical track of Beishan village. Taking the buildings of Beishan village as an example, space adding value to capital 
was reflected in the fact that farmland and traditional houses are replaced by factories and space became a server of capital. The powerful driving force of space transformation is capital involvement. The change of spatial form is also based on the requirements of capital.

At present, residents of Beishan village can use the land and real estate to collect rent. They are reluctant to engage in productive activities, and there are hidden dangers and crises that second- and third-generation permanent residents sit idle and enjoy the fruits of others' work. Beishan village's space premium is very obvious, and the rich material goods occupy people's daily lives, making it impossible for people to estimate their own space to serve for capital. It also made them have a sense of dependence on space and even believe that it was the best way to create income through space.

\section{2) Influence of capital on culture}

The injection of capital had enabled factories, houses and rental houses to be built in the same pattern. Looking from spatial architectural features, most of Beishan village's traditional architectural styles have been replaced by Western architectural styles. The original construction symbols of grey bricks and tiles in the village have been replaced. This is not reconstruction and innovation based on the original ones, but the replacement of architectural features and the invasion of foreign architectural styles, which reveals that the commodities brought by capital injection have resulted in the replacement of the products with their own national symbols, and shows the phenomenon of cultural erosion and colonization by capital.

On the other hand, the injection of capital has also injected blood into cultural protection of Beishan village. Without government planning, some investors discovered the unique historical resources of Beishan village. Therefore, they invested funds to develop cultural and creative industries in Beishan village spontaneously. The traditional buildings in Beishan village have been renovated according to the principles of protection development, and the traditional activities space has been transformed into a functional area with management, art education, exhibition, and diet. Many cultural ancient buildings such as Beishan courtyard, Beishan Hall, and Beishan Yang's Ancestral Hall in the northeastern corner of Beishan village where traditional buildings are concentrated have undergone vigorous vitality. Driven by the capital interests, the original cultural identity was lost. For the spatial perception of traditional villages, the problem of spatial homogenization was serious due to capital intervention, and the cultural crisis was intensified. If capital developed while maintaining spatial characteristics or anti-heterogeneity, there would be a good prospect for development.

\section{B. Political Criticism of Space Production}

The political criticism of space production mainly lies in the loss of spatial autonomy. Lefebvre believes that space is also a political product with a certain political ideology. The key event for the loss of space autonomy in Beishan village after the reform and opening up was the nationalization of the land acquisition in Beishan village in 1985. Land belonging to the state means that villagers' use of space must be approved by the government. If not approved by government department, any construction or use of land will be considered illegal. Through taking control of space's dominating power, the government attached Beishan village to the scope planning of Zhuhai. Therefore, the construction of Beishan village has lost its autonomy.

\section{Spatial Ecological Crisis}

\section{1) Ecological destruction of natural space}

From the perspective of natural space, the process of gradual dissolution of the relationship between the residents of Beishan village and natural space and the loss of the natural attributes of natural space reflected transformation degree that human made to nature. The farmland and fruit trees have been replaced by reinforced concrete buildings. Industrial and commercial interventions have also brought enormous air pollution, water pollution and household waste. The most serious problems in the ecological environment of Beishan village were the environmental problems in urban villages. The dense lanes were places where filth was accumulated. The fact that the number of migrants in the village are more than 20,000 makes the space extremely crowded and be surrounded by major arterial roads and secondary roads in the surrounding cities of Beishan village. However, sewage, rainwater, and other related pipelines are built on these roads. There were often problems of hydrops in rainy days and slow drainage in the village, for Beishan village belongs to low-lying areas, which was not conducive to drainage.

About $45 \%$ buildings, approximately 90 , in the Beishan village were traditional historic buildings. Due to the imperfect infrastructure in the village, some historical buildings often accumulated a large amount of domestic garbage and domestic sewage, and "the four pests" such as rats and cockroaches appeared frequently. Some historical buildings were in bad repair for a long time. However, villagers and immigrants had no protective awareness, making the historical buildings used for leasing seriously damaged and deteriorated.

\section{2) The disappearance of traditional space concepts}

The space that Lefebvre refers to is an abstract space mixed with social relations. The change of natural space not only brought about the unbalance of the natural space ecology of Beishan village, but also gradually dissolved the local residents' awareness of traditional space and culture, making the social relations of inhabitants break up. Due to the loss of spatial dominance, residents' traditional space concepts had also changed. The residents of Beishan village have reduced their sense of freedom and initiative in changing the space, which will inevitably lead to the desire that a close relationship between the people's deep desire and the space environment burst.

Taking the public space as an example, in the past, the public space in Beishan village was not clearly divided. In addition to the daily private life production, people have a lot of public space to carry out collective activities. Driven by group consciousness, people in the past transformed the 
space where people were easy to gather into public space, so they would have a strong space consciousness. Reflecting on current public activity space, people are unable to transform them with freedom. The public parks where residents live today, to a certain extent, basically the space are created by the capital and the government will. After the government took control of space production initiative, it did not stop the process of space homogenization in Beishan village. Because space regulation of government was on the macroscopic level, it is impossible to control microscopic space such as cultural heritage protection and the overall architectural style, etc. The design and form of the space are single and they are occupied by green areas of same quality and public commercial districts. It is difficult for such public spaces to maintain emotional ties, offer people a strong spatial resonance or establish a spatial concept.

\section{Space Transformation AND PlanNing Response OF BEISHAN VILLAGE}

Based on the analysis of the spatial production of Beishan village and the reference that the paper provided for the critique of spatial production, the measures and corresponding thought of space production and planning in Beishan village are proposed from following three aspects: the solution of space production problems, the balance of space production interests, and the representation of space values.

\section{A. Adhering to "People-oriented" and Paying Attention to the Development of "Space Fairness"}

To carry out space transformation, the first thing should be done is to overcome the existing space production problems. Space transformation is not simply the overall dismantlement and coverage of the old space forms, but making residents' rights be protected and enjoying better infrastructure and life services. Based on the above analysis of capital, politics, and space ecology, we can see that the studies are from the perspectives of human being. Therefore, overcoming the disadvantages of space production and constructing a livable space should take people as a starting point and make it a main purpose that helping them return to a healthy, active and happy daily life. At the same time, the space rights of residents in Beishan village, the living environment of the floating population, and the protection of local historical buildings should be paid attention to. Space fairness is to balance the interests of space production and concern the interests of the weak. Spatial transformation means a certain degree of spatial production and reconstruction. Under many spatial changes, we must adhere to the concept of people-oriented development and spatial fairness simultaneously.

\section{B. The Ways of Government Domination, Capital Power, and Villagers Participation}

Villagers, developers and government departments in Beishan village are the main stakeholders in the space production of Beishan village. The results of various contradictions arise from the fact that villagers, capital, government, or even multi-party represent different interests and values respectively. However, the goals of various interests are both compatible and conflicting. Residents are obviously disadvantaged in the game with capital and government interests.

For the sake of obtaining maximum benefits, developers representing capital will generate disputes regardless of collective interests or overall planning. For the capital, after the real estate developers obtaining land use rights, the late construction is basically controlled by themselves. Due to the lack of relevant management and controls, the large property floors were built up to the height of 10 to 20 floors, which were inconsistent with the ancient village styles and the western-style architectural style destroyed the historical and cultural atmosphere of ancient villages.

Villagers lack funds for ancient building protection, maintenance and transformation as well as later development. Some villagers carried out illegal construction activities for their own interests and to obtain more compensation for the demolition, which also severely damaged the ancient village appearance and historical buildings.

The government obtains land from villagers and divides it into various forms of capital construction or construction of public space. However, the loss of residents' interests in land acquisition activities will trigger potential conflicts of interest and have an underlying problem. That's why the government occupies a dominant position in terms of space and laws and regulations are needed to be improved as much as possible to restrict relevant conflicts of interest. At the same time, politics also should be protected by rights and interests. In particular, villagers are key producers, and their economic interests and material living environment need to be ensured.

Therefore, the government needs to analyze the balance of space interest relations and dominate the balance of space production relations in the process of researching and formulating the game rules of space production interests. The interest protection of capital must be based on the observance of the relevant space protection and development regulations formulated by the government and the maintenance of the historical and cultural resources of Beishan village. In the aspect of politics, the practice of natural space needs to be constrained and restore a good spatial ecology. Space production is inseparable from the participation of local residents. Therefore, to finish space transformation of Beishan village, residents must reach a consensus with the government to jointly restrict the power of capital.

\section{Beauty Nourishing Beishan - the Creation of Beishan Art Space}

The space beauty of Beishan village is rich in its historical and cultural heritage. There are more than 90 wellpreserved residential buildings, ancestral temple, and mansions in Qing Dynasty. These places have certain aesthetic functions and can be served as art exhibitions. The cultural beauty of Beishan village is in its heritage of folk culture, ancestral hall culture, overseas study culture and creative industry culture. The transformation of Beishan 
village needs to proceed from its own characteristics and take the development path of differentiated space.

The living functions and industrial production functions of traditional ancient buildings are inefficient, and they are places where capital and government are often unwilling to invest too much. It is precisely because that economic space and political space tend to converge and eliminate differences. Therefore, the power is needed to balance the proportion of economic space and political space and avoid the excess weight on one of the two. For art space, the traditional ancient buildings will have strong space productivity through artistic activation under a reasonable commercial operation. The vitality comes from the local protection of artistic space productivity, that is, the protection of the local residents' spiritual world.

The creation of this artistic space is inseparable from the financial support of investors with cultural feelings, as well as the government's policy support and the enthusiastic participation of villagers. Therefore, to create differential space in Beishan village, the use of rich and colorful traditional culture and historic buildings will be a very favorable entry point. Art itself is diversified, and the artistic cultural institutions of Beishan village are making artistic innovations light up the daily life of Beishan village, enriching spiritual space and maintaining good social relations.

\section{CONCLUSION}

In this paper, the theoretical value of "spatial production" runs through the text, and the relevant theoretical functions are also reflected. The appeal for space production value includes freedom, equality, justice, diversity, etc. The purpose is to highlight the space value of Beishan village. With the help of the theory of "spatial production", Beishan village was studied and the practical significance of the spatial production theory was examined. Due to the author's lack of theoretical understanding and research experience, limitation of research methods and data acquisition, the research is not studied deeply enough, and related issues need to be further analyzed. Beishan village is a village with unique characteristics and development value. It is hoped that relevant research can continue to explore the problems of artistic space and space ecology in Beishan village in depth.

\section{REFERENCES}

[1] Sun Quansheng. The Ideological Spectrum and Logical Forms of Lefebvre's Critical Theory of Space Production [J]. Journal of Jiangsu University of Science and Technology (Social Science Edition), 2014, 03:12-23.

[2] Yang Ting, Feng Jiang. Property Law, Real Right Law, Homestead Policy and Twelve Years of Heritage Protection of Beishan Village, Zhuhai [J]. Urbanism and Architecture, 2016, 10:104-107.

[3] Wang Lei. Creative Industrial Park: The Structural Force of Culture in Space Production [D]. East China Normal University, 2007.

[4] Liu Shuping. Study on the Spatial Form Evolution of Tourism Towns from the Perspective of Spatial Production [D]. Kunming University of Science and Technology, 2014.
[5] Wang Jingjun. Study on Rural Spatial Transformation and Planning Strategies Based on the New Urban-rural Relationships in South Jiangsu [D]. Suzhou University of Science and Technology, 2015.

[6] Wang Yong, Li Guangbin, Wang Chuanhai. Spatial Transformation and Planning Countermeasures of Rural Areas in South Jiangsu [J]. Planners, 2012, 04: 110-114.

[7] Chen Xiaohua, Zhang Xiaolin, Ma Yuanjun. The Transformation of China's Rural Space in the Context of Rapid Urbanization [J]. Journal of Nanjing Normal University (Natural Science Edition), 2008, 01:125-129.

[8] Gong Weixia, Zhou Jianyun. Exploration on New Planning Methods of the Socialism New Countryside Construction—-Taking Beishan Village, Nanping, Zhuhai as an Example [J]. Planners, 2007, 04:5559.

[9] Chen Xiaohua. Research on Rural Transformation and Urban-rural Spatial Integration [D]. Nanjing Normal University, 2008.

[10] Niu Jing. Rural Spatial Planning and Transformation Based on Spatial Production [J]. Urban Geography, 2016, 10:11.

[11] [11] Peng Kai. Research on China's New City in the Transformation Period Based on the Space Production Theory [D]. Huazhong University of Science and Technology, 2013.

[12] [12]Stefan Kordel. The Production of Spaces of the 'Good Life' - the Case of Lifestyle Migrants in Spain [J]. Leisure Studies,2016,35(2):

[13] [13]Mee-Kam Ng. Intellectuals and the Production of Space in the Urban Renewal Process in Hong Kong and Taipei[J]. Planning Theory \& Practice,2014,15(1). 